\title{
Study on Screening and Applying of Selective Water Shutoff Agent For Horizontal Well
}

\author{
Cui Jiali \\ Petrochina \\ Drilling \& Production Technology Research Institute of Liaohe Oilfield Company \\ Panjin, Liaoning, China \\ liurongwei2014@163.com
}

\begin{abstract}
According to the situation of water plugging in horizontal well using screen pipe completion in Liaohe oilfield, emulsion polymer gel, relative permeability correctives and oil soluble resin are studied in the paper. Three systems are evaluated in the lab. The results indicate that emulsion polymer gel is fit for point water exit of horizontal well in heterogeneous reservoir, and relative permerbility correctives are fit for multishot water exit of horizontal well in low permeability reservoir, and oil soluble resin is fit for multishot water exit horizontal well in high permeability reservoir. The effect of increasing oil in the oilfields is remarkable.
\end{abstract}

Keywords-horizontal well; selective water shutoff agent; emulsion polymer gel; relative permeability correctives; oil soluble resin

\section{INTRODUCTION}

At present, water plugging technology of the horizontal well faces three contradictions. First, the different completion methods of horizontal well put higher requirements forward for plugging agents [1]. Water plugging of casing perforated horizontal well can take the form of combining the mechanical sealing and plugging agent, which has no special requirements on the plugging agent. Second, the adaptability of plugging agent is restrict in the field. The horizontal well structure is different from the vertical wells, which horizontal section is long, and particle plugging agent in horizontal section used to accumulate. Third, the injection devices used in the field have some limitations [2]. At present, facing the contradiction of water plugging in horizontal wells, the choice of plugging agent must accord with some adverse effects, such as completion methods, self adaptability and injection devices.

Researches show that the application of selective plugging agent used in the oil field horizontal well is less [3]. In the paper, the selective plugging agents are studied. Through the lab combined with field practice, three kinds of selective plugging agent system are selected, which are emulsion polymer gel, relative permeability correctives and oil soluble resin.

\section{SCREENING AND APPLICATION OF EMULSION} POLYMER GEL SYSTEM

Through screening indoor, emulsion polymer gel has some excellent characteristics which are needed for horizontal well water plugging. Gel system is composed of polymer emulsion and LH-2 organic chromium crosslinking agent. The viscosity of crosslinking system is low before it reacts with polymer, so it is easy to inject.
The crosslinked viscosity is greater than $100 \mathrm{mPa} \cdot \mathrm{s}$, so it can go into heterogeneous formation with selectivity [4]. Polymer emulsion not only has the performance of temperature resistance, salt tolerance, higher viscosity which general polymer does not have, but also has some advantages such as dissolved quickly $(<15 \mathrm{~min})$, dissolved completely without "fish eye", and good fluidity [5]. The main performance index of emulsion polymer is shown in TABLE I .

TABLE I. MAIN PERFORMANCE INDEX OF EMULSION POLYMER

\begin{tabular}{|c|c|}
\hline Items & Index \\
\hline appearance & $\begin{array}{c}\text { white water dispersed } \\
\text { evenly liquid }\end{array}$ \\
\hline $\mathrm{pH}$ value & $4 \sim 6$ \\
\hline density, $\mathrm{g} / \mathrm{cm}^{3}$ & 1.1 \\
\hline solid content, $\%$ & 40 \\
\hline degree of hydrolysis,$\%$ & 20 \\
\hline molecular weight, $10^{4}$ & 900 \\
\hline
\end{tabular}

A. Dissolution time of emulsion polymer

It is common to use conductivity method for measuring emulsion polymer dissolution time, and experimental process is as follows. Prepare $5000 \mathrm{mg} / \mathrm{L}$ emulsion polymer solution, and put conductivity meter probe into solution, and record a solution conductivity value every minute until the conductivity values remain unchanged within 5 min.

Emulsion polymer was dissolved in sewage of Liaohe Oilfield. At the beginning, water conductive ability was strong, and conductivity decreased with the continuous dissolution of polymer emulsion, finally conductivity tended to be stable. The inflection point is the dissolution time of the polymer. The results of conductivity are shown in Fig .1.

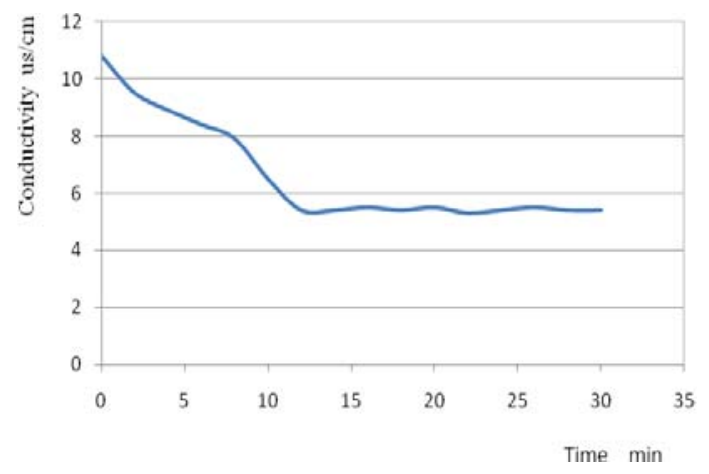

Figure 1. Dissolution time test 
From the experimental results we can know that the dissolution time of the emulsion polymer is lower than $15 \mathrm{~min}$ in the sewage, which is favorable for the rapid preparation in the field.

\section{B. Shear resistance of emulsion polymer}

Took Gaol block sewage to prepare the emulsion polymer, and the concentrations were 1500, 2000, 2500 $\mathrm{mg} / \mathrm{L}$. The polymer solution went through the anti-sand equipment under $0.5 \mathrm{MPa} \mathrm{N}$, and measured shear viscosity of the solution. The results are shown in TABLE II .

TABLE II. EXPERIMENTAL RESULTS ON THE SHEAR RESISTANCE OF EMULSION POLYMER SOLUTION

\begin{tabular}{|c|c|c|c|}
\hline $\begin{array}{c}\text { Polymer } \\
\text { concentration, } \\
\mathbf{m g} / \mathbf{L}\end{array}$ & $\begin{array}{c}\text { Initial } \\
\text { viscosity, } \\
\mathbf{m P a} \cdot \mathbf{s}\end{array}$ & $\begin{array}{c}\text { Shear } \\
\text { viscosity }, \\
\mathbf{m P a} \cdot \mathbf{s}\end{array}$ & $\begin{array}{c}\text { Viscosity } \\
\text { retention } \\
\text { rate, } \%\end{array}$ \\
\hline 1500 & 10.5 & 8.7 & 82.9 \\
\hline 2000 & 13.4 & 10.9 & 81.3 \\
\hline 2500 & 16.9 & 13.7 & 81.1 \\
\hline
\end{tabular}

The results show that the polymer emulsion has stronger shear resistance. With the increasing polymer concentration, viscosity retention rate is on a downward trend. The emulsion polymer shear viscosity retention rate is more than $80 \%$.

\section{Optimization experiment of the emulsion polymer gel formulation}

The experimental method of formulation optimization is as follows. Gaol block sewage was used to dissolve the emulsion polymer, and the temperature was $70^{\circ} \mathrm{C}$. The polymer concentration of emulsions were 1500, 1800, 2000, 2200, 2500, 3000, 4000mg/L. LH-2 organic chromium crosslinking agent concentrations were 800 , $1000 \mathrm{mg} / \mathrm{L}$. Added LH-2 organic chromium crosslinking agent into the certain concentration of emulsion polymer solution, and shaked the system evenly, then put the system into incubator kept $72 \mathrm{~h}$ at $70^{\circ} \mathrm{C}$. The viscosity of polymer solution was measured by RS150 rheometer model, and the viscosity of crosslinking system was measured by RS150 rheometer at oscillation mode. Experimental results are shown in Fig .2.

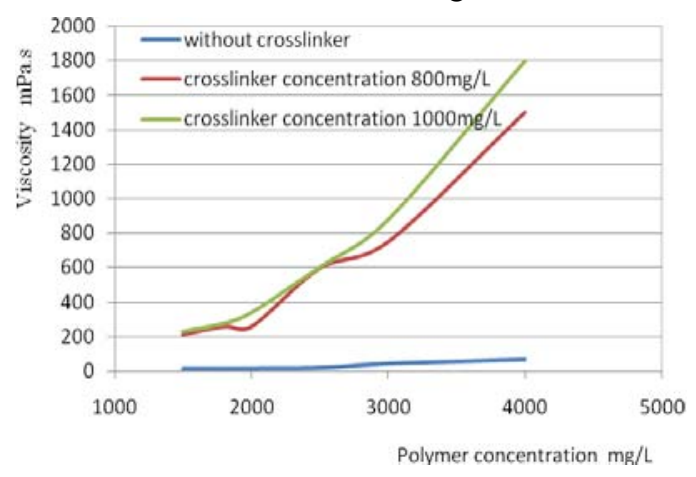

Figure 2. Experimental results of cross linking at different concentration $\left(70^{\circ} \mathrm{C}\right)$

The experimental results show that the emulsion polymer can crosslink effectively with LH-2 organic chromium crosslinking agent in Gaol block sewage. The viscosity of the system increases obviously. With the concentration of polymer and crosslinking agent increasing, the viscosity of the system increases.
Considering the strength requirements of water shutoff agent used in the horizontal well, combined with the laboratory evaluation results, polymer emulsion frozen gel system formula is determined as follows: emulsion polymer concentration is greater than $4000 \mathrm{mg} / \mathrm{L}$, and LH-2 organic chrome crosslinking agent concentration is greater than $1000 \mathrm{mg} / \mathrm{L}$.

\section{Thermal stability of emulsion polymer}

Polymer emulsion frozen gel was prepared as follows: took Gaol block sewage to dissolve polymer emulsion, and polymer concentration was $2000 \mathrm{mg} / \mathrm{L}$, and crosslinking agent concentration was $1000 \mathrm{mg} / \mathrm{L}$. The temperature was $70^{\circ} \mathrm{C}$. After gelled, the system was kept for 90 days at $70^{\circ} \mathrm{C}$, and the viscosity retention rate was still larger than $70 \%$. Experimental results are shown in Fig .3.

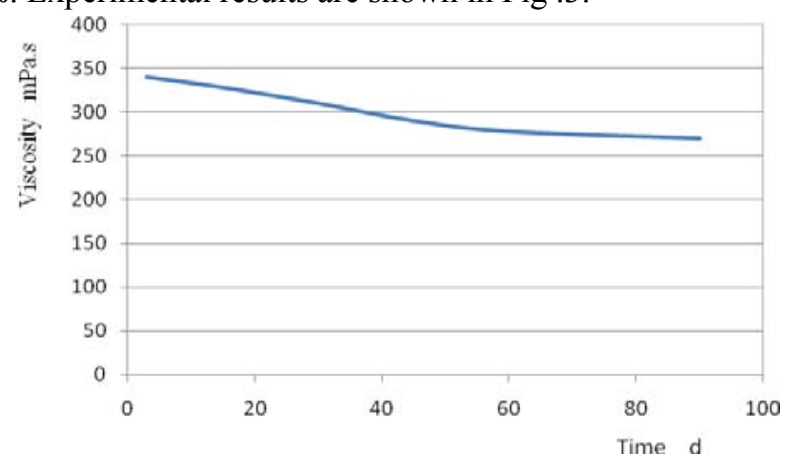

Figure 3. Thermal stability of emulsion polymer gel system

\section{E. Field application of emulsion polymer gel system}

Take Gao1-P1well for example. According to the analysis of drilling trajectory data, the end of the horizontal section of the vertical depth is too low, and the horizontal section is near the level of oil water interface. There is active water at the edge and bottom. Because of above the bottom water of the reservoirs without tight layer, and reservoir permeability is heterogeneity in vertical, the formation water whose flow resistance is relatively small is more easily to go into the wellbore in the same production pressure. It can be concluded that flow channel has been formed.

In the field, the emulsion polymer gel system was used to implement for horizontal well water shutoff. It was injected by using the light pipeline. The total intake volume was $1550 \mathrm{~m}^{3}$. The injection rate was $5.0 \mathrm{~m}^{3} / \mathrm{h} \sim$ $8.0 \mathrm{~m}^{3} / \mathrm{h}$. The initial pressure was 0 , and the maximum pressure was $7.8 \mathrm{MPa}$. After water plugged, daily oil production rose from $2.5 \mathrm{t}$ to $27.1 \mathrm{t}$ and water cut decreased from $70 \%$ to $98.2 \%$. The production oil of the well accumulated 2440t. The effect of increasing oil was remarkable.

\section{EVALUATION OF RELATIVE PERMEABILITY CORRECTIVES}

The mechanism of relative permeability correctives are changing the wettability of rock surface and increased water flow resistance. Relative permeability correctives have the following properties [6]. First, it can be firmly adsorption in the stratum needed water control. Second, the molecule of relative permeability correctives can stretch when it encounters water, and it can form a stable 
network structure, which can increase resistance of water molecules passing through. Third, when it encounters oil molecules, relative permeability correctives molecular system contracts, which can reduce the resistance of crude oil passing by. Fourth, relative permeability correctives molecule on demanding environment can exist stably without decomposition [7]. Fifth, it can reverse the rock surface wettability, which leads the crude oil molecules can not adsorbed on the surface of the rock. These properties can meet the selective plugging water requirements of the low permeability reservoir, multipoint water outlet and pipe completion for horizontal well. Therefore, the evaluation are carried out indoor.

\section{A. Evaluation method}

\section{1) Test equipment and materials}

Core flow experimental instrument, pressure sensor and pressure gauge, different permeability artificial core filled with quartz sand, crude oil, kerosene, simulated formation water (salinity is $5727 \mathrm{mg} / \mathrm{L}$ ).

2) Test procedure

a) Measure the change rate of water phase permeability

Measure the water phase permeability before injection; inject $1 \mathrm{PV} \quad 0.5 \%$ relative permeability correctives in opposite directions; keep static $24 \mathrm{~h}$; inject simulated water; measure the water phase permeability after injection.

b) Measure the change rate of oil phase permeability

Measure the oil phase permeability before injection; inject $1 \mathrm{PV} \quad 0.5 \%$ relative permeability correctives in opposite directions; keep static $24 \mathrm{~h}$; inject simulated oil; measure the oil phase permeability after injection.

B. Determination of water phase permeability, plugging rate, and oil recovery rate

1) Change rate of oil phase permeability

The parameters of artificial core filled with quartz sand are shown in TABLE III.

TABLE III. THE PARAMETERS OF ARTIFICIAL CORE FILLED WITH QUARTZ SAND

\begin{tabular}{|c|c|c|}
\hline Parameters & $\begin{array}{c}\text { Single tube } \\
\text { model 1 }\end{array}$ & $\begin{array}{l}\text { Single tube } \\
\text { model 2 }\end{array}$ \\
\hline diameter, cm & 2.5 & 2.5 \\
\hline length, $\mathrm{cm}$ & 19.0 & 19.0 \\
\hline permeability, $\times 10^{-3} \mu^{2}$ & 516.1 & 610.2 \\
\hline pore volume, $\mathrm{mL}$ & 16.0 & 17.0 \\
\hline
\end{tabular}

The test temperature is $70^{\circ} \mathrm{C}$, and the relative permeability correctives injection rate is $2 \mathrm{~mL} / \mathrm{min}$. The decline rate of oil phase permeability is $25 \%$ (plugging oil rate). The test results are shown in TABLE IV.

TABLE IV. TEST RUSULTS

\begin{tabular}{|c|c|c|c|}
\hline No. & $\begin{array}{c}\text { Pemeability } \\
\text { before plugging } \\
\mathbf{K} \mathbf{1}, \times \mathbf{1 0}^{-3} \boldsymbol{\mu \mathbf { m } ^ { \mathbf { 2 } }}\end{array}$ & $\begin{array}{c}\text { Pemeability } \\
\text { after plugging } \\
\mathbf{K} \mathbf{2}, \times \mathbf{1 0}^{-3} \boldsymbol{\mu \mathbf { m } ^ { \mathbf { 2 } }}\end{array}$ & $\begin{array}{c}\text { Plugging } \\
\text { rate, } \%\end{array}$ \\
\hline 1 & 516.1 & 389.1 & 24.6 \\
\hline 2 & 610.2 & 455.2 & 25.4 \\
\hline
\end{tabular}

2) Change rate of water phase permeability

The parameters of artificial core filled with quartz sand are shown in TABLE $\mathrm{V}$.
TABLE V. THE PARAMETERS OF ARTIFICIAL CORE FILLED WITH QUARTZ SAND

\begin{tabular}{|c|c|c|}
\hline Parameters & Single tube model 3 & Single tube model 4 \\
\hline diameter, cm & 2.5 & 5 \\
\hline length, cm & 19 & 52 \\
\hline Pore volume, $\mathrm{mL}$ & 15 & 237.7 \\
\hline
\end{tabular}

The test temperature is $70^{\circ} \mathrm{C}$, and the relative permeability correctives injection rate are $2 \mathrm{~mL} / \mathrm{min}$ and 5 $\mathrm{mL} / \mathrm{min}$. The decline rate of water phase permeability is $90.3 \%$ and $95.5 \%$ (plugging water rate). The test results are shown in TABLE VI.

TABLE VI. TEST RUSULTS

\begin{tabular}{|c|c|c|c|}
\hline NO. & $\begin{array}{c}\text { Pemeability } \\
\text { before plugging } \\
\mathbf{K} \mathbf{3}, \times \mathbf{1 0}^{-\mathbf{3}} \boldsymbol{\mu m}^{\mathbf{2}}\end{array}$ & $\begin{array}{c}\text { Pemeability } \\
\text { after plugging } \\
\mathbf{K} \mathbf{4}, \times \mathbf{1 0}^{-3} \mathbf{\mu m}^{\mathbf{2}}\end{array}$ & $\begin{array}{c}\text { Plugging } \\
\text { rate, } \%\end{array}$ \\
\hline 3 & 1032.2 & 100.1 & 90.3 \\
\hline 4 & 1324.8 & 60.2 & 95.5 \\
\hline
\end{tabular}

From above experiments, it can be seen that the relative permeability correctives can plug water effectively, and the sealing rate of oil is very low. Therefore, it can play an effective role in adjusting water phase permeability, and the performances are fit for requirements of selective plugging agent.

\section{IV.SCREENING AND EVALUATION OF OIL SOLUBLE RESIN}

Oil soluble resin is a kind of synthetic material, which has the characteristics of being dissolved in oil, but not in water. It is an ideal material for selective water shutoff agent. Main parameters of oil soluble resin are shown in TABLE VII. Oil soluble resin has some structural strength itself, and it has the priority to go into the high permeability and high permeability formation. In the process of oil production, oil soluble resin can be dissolved in oil and can not react with water [8]. Depending on the characteristics of oil soluble resin, it can meet horizontal wells selective plugging water requirements. The evaluation were carried out indoor.

TABLE VII. MAIN PARAMETERS OF OIL SOLUBLE RESIN

\begin{tabular}{|c|c|}
\hline Items & Parameters \\
\hline appearance & faint yellow or sandy beige suspension liquid \\
\hline $\mathrm{pH}$ value & $6 \sim 8$ \\
\hline density, $\mathrm{g} / \mathrm{cm}^{3}$ & $1.0 \sim 1.15$ \\
\hline solid content, $\%$ & $\geq 25$ \\
\hline
\end{tabular}

\section{A. Particle size distribution}

Particle size analysis of oil soluble suspension was carried out by laser particle size instrument. The particle size in 3-8 um of the solid particles accounted for $83 \%$ in the oil soluble resin system. It is the main component of the system. A small portion of solid particles is not in the range of the system. More than 8 um accounted for $8 \%$, and less than 3 um accounted for $9 \%$. But the total accounted for less than $20 \%$. In field application, we can select the suitable oil soluble resin according to the actual reservoir characteristics and temperature. Oil soluble resin must be prepared to match with the reservoir pore throat size [9]. 


\section{B. Selective evaluation}

In order to investigate the selective sealing ability of oil soluble resin suspension, some experiments are carried out in the laboratory.

Experimental preparation and conditions. The oil soluble resin suspension concentration was $10 \%$, and the system was diluted with water. The experimental temperature was $70{ }^{\circ} \mathrm{C}$. The cores used in experiment were artificial cores, and No.5 core and No. 6 core were artificial filled with sand. Simulating water was used to drive, whose mineralization was $5000 \mathrm{mg} / \mathrm{L}$. The flooding oil was simulating oil, and the main ingredient is kerosene.

Experiment process [10]. The core was accessed in the process; saturated with water; measured the pore volume; measured the water phase permeability Kw1 after it was stable (agreed for the forward). Then the core was saturated with oil, and the irreducible water saturation was established. Measured the oil phase permeability Ko1. Inject water to water content of $98 \%$; inject $10 \%$ concentration of the oil soluble resin suspension 1PV; and inject water forward to flow state stability; measure the water phase permeability Kw2; inject oil forward to flow state stability; measure the oil phase permeability Ko2. From the experimental results, it can be seen that different permeability core plugging rate was more than $96 \%$. Inject oil in the opposite direction, and oil soluble resin dissolved by oil slowly, the permeability recovery value can reach more than $90 \%$, thus oil soluble resin has excellent selective plugging effect.

\section{CONCLUSIONS}

1) In the horizontal well water plugging field conditions, in order to meet the screen pipe completion requirement, emulsion polymer gel system, the relative permeability correctives and oil soluble resin plugging agent system are screened. And the three systems have strong adaptability, which can satisfy the screen completion for horizontal well selective water plugging requirements.

2) Emulsion polymer gel not only has the performance of temperature resistance, salt tolerance, higher viscosity, but also has some advantages such as dissolved quickly, dissolved completely, and good fluidity, so it is fit for point water exit of horizontal well in heterogeneous reservoir

3) Relative permeability correctives are changing the wettability of rock surface and increased water flow resistance, and have low viscosity. They are fit for low permeability reservoir.

4) Oil soluble resin has many good characters, such as it can be soluble in oil but not in water, and particle size can be adjusted, and selective plugging performance is good. It is fit for high porosity and high permeability reservoirs.

\section{REFERENCES}

[1] Li Yi-kun, HU Pin, Feng Jilei. Background, current situation and trend of development for water shutoff in horizongtal wells [J]. Journal of Oil and Gas Technology, 2005, 27(5): 757-761.

[2] Liu Rong-wei. Study and application of in-depth profile modification and flooding technology in water-flooding reservoir [J]. Advances in Fine Petro-chemicals, 2011, 12(10)12-15.

[3] Al-Muntasheri, G. A., Nasr-El-Din, H.A., Zitha, P. L. J. Gelation Kinetics and Perfor-mance Evaluation of an Organically Crosslinked Gel at High Temperature and Pressure [J]. SPEJ, 13(3): 337-345.

[4] Ye Yin-zhu, Wu Xing-cai, Wang Zheng-bo, Deve-lopment of movable gel system and mechanism analysis [J]. Petroleum Geology and Engineering, 2010, 24(3): 73-75.

[5] Wan Jia-gui Fan Zhen-zhong Wang Bing-kui, Study and application of a selective plugging agent for oilfields [J]. Advances in Fine Petrochemicals, 2005, 7(2): 16-19.

[6] Yuan Shi-yi, Han Dong, Mao Kun. Application of flowing gel profile control technique to complex block reservoir [J]. Acta Petrolei Sinica, 2004, 25 (4): 50-57.

[7] Harry L. Chang, Xingguang Sui, Long Xiao, et al. Successful field pilot of in-depth colloidal dispersion gel (CDG) technology in daqing oil field, SPE 89460-PA, 2006.

[8] K. Spildo, A. Skauge, M.G. Aarra, M.T. Tweheyo. A New Polymer Application for North Sea Reservoirs. SPE,113460- PA, 2009.

[9] Ganguly, S., Willhite, G.P., Green, D.W., McCool, C.S.. The effect of fluid leakoff on gel placement and gel stability in fractures $[\mathrm{J}]$. SPE J. 2002, 7 (3), 309-315.

[10] James J. Sheng. Modern chemical enhanced oil recovery: theory and practice [M]. Boulevard: Gulf Professional Publishing, 2011. 